\title{
On the Capability of Heat Dissipation in Thermally Aged Electrical Machines
}

\author{
Vincenzo Madonna, Paolo Giangrande and Michael Galea
}

\begin{abstract}
Thermal aging is one of the main causes of progressive deterioration of the insulation system in electrical machines. This because the thermo-physical properties of dielectric materials can undergo severe changes when exposed to high temperature. Accordingly, thermal aging has a twofold effect, namely, shortening the expected insulation lifetime and influencing the heat transfer / dissipation towards the surrounding. This paper aims at analyzing the second aspect through an in-depth experimental investigation. A case-study motor is thermally modelled with the purpose of quantifying the extent and magnitude of thermal conductivities change, resulting from the insulation thermal aging. As an outcome, it is found that the hot-spot temperature in a thermally-aged machine can be considerably higher than its unaged counterpart, for given operating and boundary conditions.
\end{abstract}

Index Terms-Thermal Analysis, LPTN, Aging, Physics of Failure, Design of Experiments

\section{INTRODUCTION}

Now more than ever, electrical machines (EMs) are expected to achieve outstanding performances. With the progressive shift towards (more) electrified transportation, EM designers are facing a number of challenges for meeting power density targets, dictated by global electrifications roadmaps / targets $[1,2]$. Every minimum save in terms of weight has a strong impact on the fuel consumption for both ground and air transportation. With the transition to hybrid- / full- electric vehicles, the issue is becoming even more relevant, given the objective energy density limitations of current electrochemical energy storage devices [3].

It is a common belief within the scientific community that a number of technology-enablers will, in the near future, contribute in achieving power and torque density targets [4]. These enablers include superconductivity, additive manufacturing, unconventional cooling methods, high temperature insulating materials etc...[5]. However, today, most of them are still limited to very specialized niche applications and prototypes [6-9].

Considering a conventional, state-of-the-art EM there are various ways for boosting the power density performance. Clearly, if the target is only incrementing the power-to-weight ratio, then, a straightforward solution is to operate the EM at high speed. Such kind of operating condition is currently facilitated by the availability of fast-switching power electronics converters (i.e., employing silicon carbide or

This work was partially funded from the Clean Sky 2 Joint Undertaking under the European Union's Horizon 2020 research and innovation programme under grant agreement no. 807081 .

This work was also partially funded by the University of Nottingham Propulsion Futures Beacon. (Corresponding Author: Vincenzo Madonna)

V. Madonna, P. Giangrande and M. Galea are with the Power Electronics, Machines and Control Research Group (PEMC), University of Nottingham, UK. (email: Vincenzo.madonna1@nottingham.ac.uk)

M. Galea is also with the Key Laboratory of More Electric Aircraft Technology of Zhejiang Province, Ningbo 315100, China. gallium nitride power semiconductors), and high-strength, low loss soft magnetic materials. Nevertheless, in some cases (e.g., aerospace propulsion), the EM needs to deliver a large torque level at relatively low speeds. In this scenario, what mostly constrains the maximum achievable torque is surely the thermal limit [10]. The latter is directly related to the maximum safe temperature at which electrical insulating materials can operate, and it is commonly identified with the EM's thermal class.

An accurate thermal modeling in EM design is thus crucial for avoiding over-temperatures, which might excessively stress the insulation system shortening the EM lifetime, and eventually leading to premature / unexpected faults. Conversely, a precise temperature prediction of the EM's hot-spot allows to exploit at their best the capabilities of insulating materials, reducing as much as possible any over-engineering measure.

Lumped parameters thermal networks (LPTNs) are computationally efficient tools for estimating the temperature distribution in EMs [11]. In an LPTN the whole machine or just a portion of it can be thermally modeled, by a network of thermal resistances, capacitances, and heat / temperature sources [12]. When only the winding temperature needs to be predicted, a common choice is to build a reduced-order LPTN [13]. On the contrary, when a superior fidelity is essential, highly discretized LPTNs need to be developed. That is, subdividing the whole volume in a dense mesh of thermal nodes. In this latter case, the denser is the mesh, the more the LPTN resembles a finite element (FE) model.

Accordingly, a FE model is generally considered to be more accurate than a simplified LPTN. This comes at the cost of an increased computational burden, particularly during the pre-processing stage (i.e., geometry construction and meshing operations). A similarity characterizes both LPTNs and FE models, namely, the demand for a precise knowledge of a) EM geometrical dimensions, and b) materials' thermophysical properties (in particular thermal conductivities). In fact, if these quantities are unknown or imprecise, the temperature prediction accuracy is compromised.

Unfortunately, very often, materials' thermo-physical data are unavailable or inaccurate, thus, an experimental fine-tuning is required for both LPTNs and FE models. Such a procedure is conventionally carried out during the very early stage of the design process, adopting motorettes / formettes, whose geometry and materials are the same of the EM being designed. This approach, in principle, might seem reasonable, although, it could potentially lead to an erroneous model, since it is based on the assumption that materials' thermal conductivities will remain unchanged throughout the EM service lifespan. This assumption might be correct for the winding's core (i.e., copper), lamination stack, and other metallic parts / bodies. However, the electrical insulation system is highly susceptible to the effects of aging (in 
particular thermal aging). Thus, as the EM ages, its heat dissipation capability might vary with respect to the unaged condition.

This paper experimentally investigates how thermal aging can impact on the heat transfer within an EM. A naturally aircooled permanent magnet synchronous machine (PMSM) is selected as study-case for supporting the investigation. The latter is thermally modeled via both a reduced-order LPTN and a simplified 2D FE model. Then, after performing accelerated thermal aging tests on representative motorettes, it is verified how the temperature predictions provided by both thermal models are strongly influenced by the thermal aging, meaning that the EM's thermal behavior varies as the insulation system ages.

\section{CASE-STUDY PMSM}

This Section introduces the case-study PMSM which is utilized throughout the paper for assisting the presented investigation.

The EM is a 12 slot / 10 pole surface mount PMSM, originally designed for an aerospace actuator. Because of the safety-critical nature of the application [14], the motor features a single layer concentrated winding and it can be operated either as a conventional three-phase machine, or as a dual-three phase one. Being the winding concentrated, at alternated teeth (i.e., single layer), the probability of interphase winding short-circuit is minimized. Additionally, by supplying each of the three-phase winding sets through an independent power converter, fault tolerance capabilities are enabled. The 3D view of the case-study PMSM is sketched in Fig. 1, while the main design parameters are listed in Table I.

Two motorettes, mirroring half of the PMSM's stator (both in terms of geometry, winding layout and materials) have been manufactured and they are shown in Fig. 2. These will be thermally modelled in Section III and used for testing purposes in Section IV.

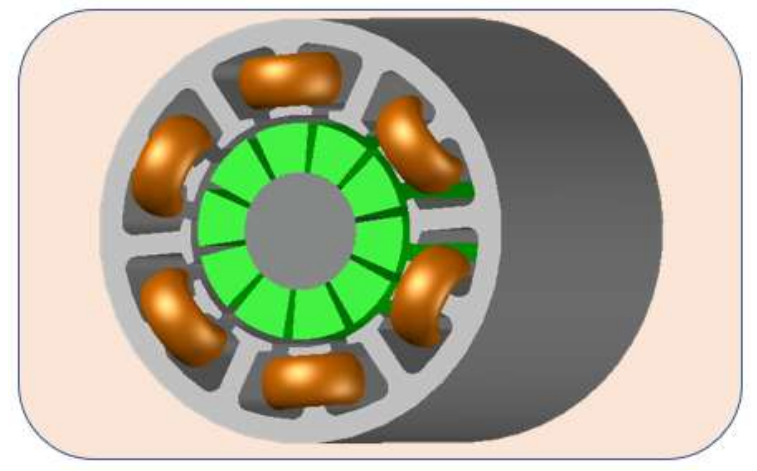

Fig. 1. 3D view and winding layout of the case-study PMSM.

TABLE I

MaIn Design PaRAMETERs OF THE CASE-STUdy PMSM

\begin{tabular}{cc}
\hline \hline Parameter & Data \\
\hline Slot number & 12 \\
Pole number & 10 \\
Axial length & $83 \mathrm{~mm}$ \\
Stator outer diameter & $60 \mathrm{~mm}$ \\
Winding configuration & Concentrated \\
Turns per coil & 80 \\
Winding wire bare diameter & $0.400 \mathrm{~mm}$ \\
Winding wire grade & Grade 2 \\
Insulation thermal class & $200{ }^{\circ} \mathrm{C}$ \\
Impregnation & VPI epoxy resin \\
\hline \hline
\end{tabular}

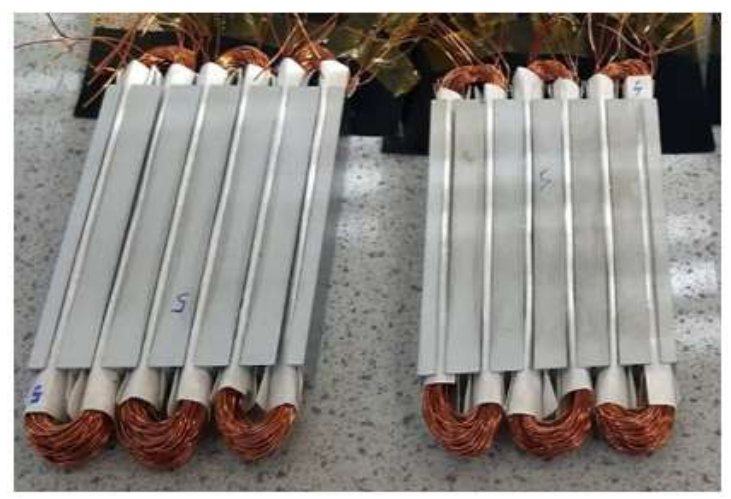

Fig. 2. Motorettes mirroring the case-study PMSM's stator.

\section{Thermal Modeling OF THE CASE-STUdy PMSM}

In this Section two different thermal models for the motorettes shown in Fig. 2 are implemented. The first model is a two-node LPTN, whilst the second one is a FE model of the motorette's slot. The two proposed models will be exploited in Section $\mathrm{V}$ for investigating how thermal aging can affect the heat transfer within an EM.

\section{A. Reduced-Order LPTN}

In several cases when thermally-modeling an EM, the main objective is to predict the winding temperature profile, which is where the hot-spot is commonly placed. The lifetime of the insulation system, and thus the EM's reliability, is strongly influenced by the accuracy of the modeling technique. Indeed, any over-temperature above the insulation thermal class might accelerate dielectric materials degradation, leading to premature failures.

LPTNs are probably the most largely employed tool for the thermal analysis of EMs. For the assessment of the winding temperature profile, a reduced order LPTN is often developed. Such a simplified model, clearly, limits the volumetric discretization of the temperature prediction, but, on the other hand, it has a minimal computational burden. In this work a second-order LPTN is adopted, which is built as illustrated in Fig. 3. Only two thermal resistances and as many capacitances form the whole network. $R_{e q}$ is the equivalent conduction thermal resistance between the node at the highest temperature $\theta_{h s}$ and the stator outer surface. The second one is a convection resistance $R_{\text {conv }}$ between the stator's outer surface and the ambient air temperature source $\theta_{\text {amb }}$. The thermal capacitance $C_{\text {short }}$ is needed for modeling short-duty transients (i.e., the initial part of the temperature profile). On the contrary, $C_{\text {long }}$ is included for modeling longer thermal transients, where the large thermal inertia of the stator core contributes to the slow-rising (or slow-falling) hot-spot temperature profile. With $\theta_{\text {ext }}$ it is finally indicated the stator core outer temperature, that is assumed to be uniform over the entire external surface area.

In Fig. 3, only the Joule losses are considered through a single heat source (i.e., $P_{J}$ ). This choice enables the use a DC excitation during calibration thermal tests, which is the common practice $[15,16]$. Consequently, $P_{J}$ is computed as in (1), where $I_{D C}$ is the winding DC current, $n$ is the number of turns, $L$ is the active length of the lamination stack, $\rho(\theta)$ is the copper resistivity at temperature $\theta$ and $S_{\text {cond }}$ is the conductor cross-sectional area.

$$
P_{J}=6 \cdot I_{D C}^{2} \cdot n \cdot L \cdot \rho(\theta) / S_{\text {cond }}
$$


For the sake of computational simplicity, (1) presumes that all the heat generated within the end winding volume is directly dissipated to the ambient through convection.

When transient thermal calibration tests are performed using a fixed DC current (as in the case of this work), the winding resistivity rises proportionally with the instantaneous winding temperature based on (2), where $\alpha$ is a constant equal to $3.93 \cdot 10^{-3}{ }^{\circ} \mathrm{C}^{-1}$ [17] and $\rho\left(0{ }^{\circ} \mathrm{C}\right)$ is the copper electrical resistivity at $0{ }^{\circ} \mathrm{C}$.

$$
\rho(\theta)=\rho\left(0{ }^{\circ} \mathrm{C}\right) \cdot\left[1+\alpha\left(\theta-0{ }^{\circ} \mathrm{C}\right)\right]
$$

In the present investigation, such an effect is accounted for through the block scheme shown in Fig. 4. The latter is implemented in Matlab ${ }^{\circledR}$ Simulink $^{\circledR}$, and allows for the precise resistivity computation, according to the instantaneous winding temperature.

In Section IV the numerical value of the LPTN's resistances and capacities will be experimentally estimated, by performing DC calibration tests on the unaged motorettes.

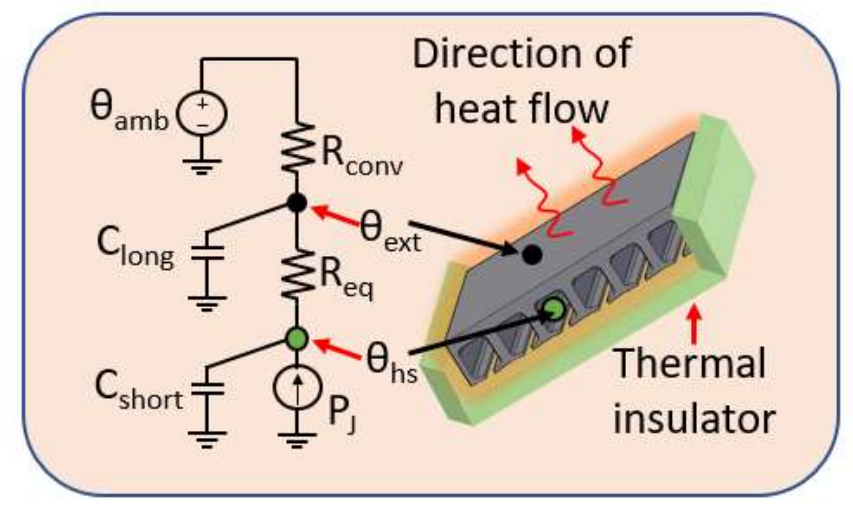

Fig. 3. Reduced-order LPTN of the case-study PMSM.

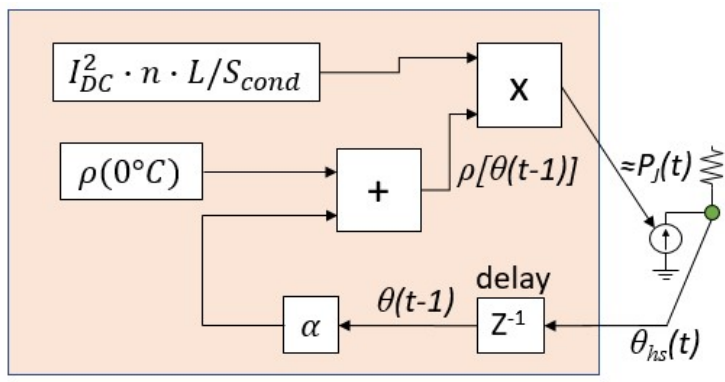

Fig. 4. Block diagram for dynamic resistivity computation.

\section{B. Finite Element Thermal Model}

The LPTN described in Section III.A has the objective benefit of an extremely simple structure. It can thus satisfactorily fulfil the general task of hot-spot temperature prediction for the case-study PMSM. Its main limitation is however the inability to provide any kind of temperature distribution within the EM slot. Such a requirement can be then satisfied by the simple FE thermal model, which has been implemented in ANSYS Mechanical ${ }^{\circledR}$, and whose structure and mesh can be visualised in Fig. 5. Because of the symmetrical structure, only $1 / 6^{\text {th }}$ of the motorette is modelled. The magnitude of the internal heat generation within the slot (i.e., Joule loss) is rescaled accordingly. Free convection is imposed as boundary condition for top edge of the structure (i.e., stator outer surface), whilst a perfect insulation is assumed for the three remaining sides (i.e., slot bottom/opening and two half teeth).
The slot is thermally modelled as a multi-material compound, through an equivalent "homogenised" conductivity $k_{w}$, which incorporates:

1. Winding's copper core conductivity in the radial and tangential directions;

2. Winding insulation (i.e., magnet wire enamel);

3. Epoxy impregnation;

4. Air gaps within the winding.

The precise analytical computation of $k_{w}$ is not a trivial task, mainly because of it being strongly dependent upon the manufacturing process through the "impregnation goodness", namely, a figure inversely proportional to the volumetric ratio resin / air inclusions. For this reason, $k_{w}$ will be quantified through experimental tests in Section IV.

For the sake of simplicity, a "bonded" contact region is used between the winding and the iron core. This reduces the number of parameters to be experimentally evaluated, and minimizes the computational time. In reality, the slot liner, and potentially the liner-core interference gap, should also be modelled. Nonetheless, this simplification does not have a crucial impact on the temperature prediction accuracy. Indeed, it will only lead to a slightly lower equivalent slot conductivity value in the FE model (with respect to that of the actual EM).

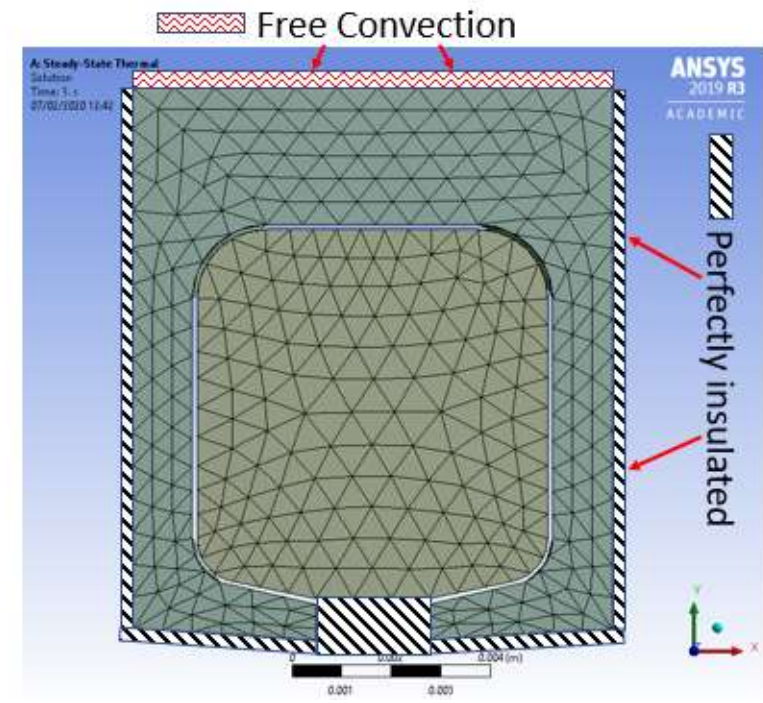

Fig. 5. Thermal FE model of the PMSM slot: geometry, mesh and boundary conditions.

\section{EXPERIMENTAL CALIBRATION: UnAGED CASE}

In this Section both the LPTN and FE model discussed in Section III are experimentally-calibrated through DC tests performed on unaged motorettes.

\section{A. Test description}

Two motorettes, identical to those shown in Fig. 2, are manufactured and instrumented with six K-type thermocouples, distributed in key locations. The prototypes are then thermally-insulated towards the slot-opening and on the lateral sides using Superwool ${ }^{\circledR} 607^{\circledR} \mathrm{HT}^{\mathrm{TM}}$, following the layout provided in Fig. 3. Finally, they are placed inside an environmental chamber Memmert UF260plus as can be seen in Fig. 6. Their windings are then connected to a programmable DC power supply in line with the scheme depicted in Fig. 7.

A trial and error exercise is initially carried out for a) 
detecting the thermocouple that records the highest temperature (i.e., $\approx \theta_{h s}$ ) and $\mathrm{b}$ ) identifying the maximum DC current to be injected in the windings, which satisfies (3) for an ambient temperature of $30{ }^{\circ} \mathrm{C}$, where $t_{s s}$ is a timespan sufficiently long for attaining thermal equilibrium (i.e., steady-state conditions).

$$
\theta_{h s}\left(t_{s s}\right)<\text { Thermal class }
$$

Point b) is necessary for avoiding any extrinsic (i.e., "unwanted") insulation thermal aging throughout the testing campaign. The inequality provided by (3) is found to be satisfied when $I_{D C}$ is equal to $1.5 \mathrm{~A}$ (and obviously for any current below this value).

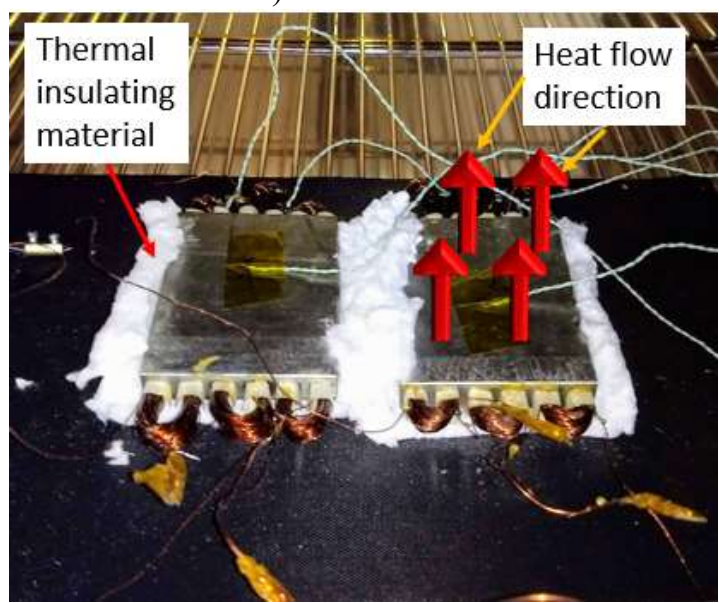

Fig. 6. Instrumented motorettes inside the environmental chamber.

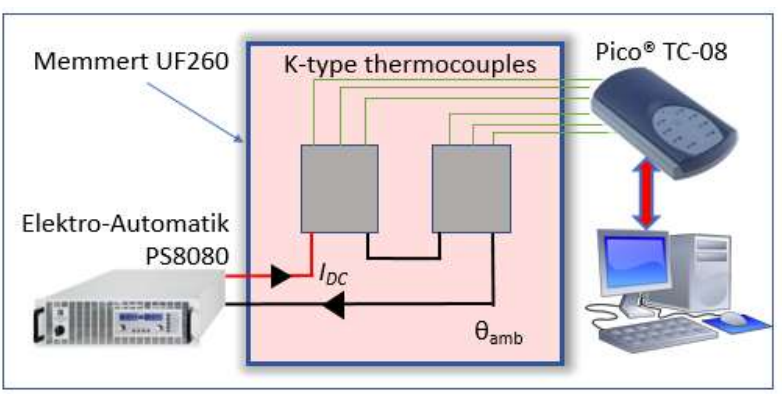

Fig. 7. Schematic of the experimental test-bench.

\section{B. LPTN calibration}

The environmental chamber temperature is set to $\theta_{a m b}=30$ ${ }^{\circ} \mathrm{C}$ and after the motorettes reached the thermal equilibrium, their windings are fed through a DC current of $1.5 \mathrm{~A}$. Simultaneously, the thermocouples' temperature profiles are recorded using a data-logger connected to a personal computer, as illustrated Fig. 7. The temperature profiles are imported in Matlab ${ }^{\circledR}$, where the LPTN shown in Fig. 3 is also implemented. The Simulink ${ }^{\circledR}$ Parameter Estimation toolbox is then employed for finding the values of $R_{e q}, R_{c o n v}, C_{\text {short }}$ and $C_{\text {long }}$, which minimize the squared error between measured and the LPTN-predicted temperatures. This task is achieved via a Sequential Quadratic Programming (SQP) algorithm. The optimized values for each of the LPTN elements are listed in Table II.

TABLE II

OPTIMIZED THERMAL PARAMETERS FOR THE UNAGED LPTN

\begin{tabular}{cc}
\hline \hline Parameter & Value \\
\hline$R_{e q}$ & $9.35 \mathrm{~K} / \mathrm{W}$ \\
$R_{\text {conv }}$ & $64.2 \mathrm{~K} / \mathrm{W}$ \\
$\mathrm{C}_{\text {short }}$ & $2.82 \mathrm{~J} / \mathrm{K}$ \\
$\mathrm{C}_{\text {long }}$ & $11.6 \mathrm{~J} / \mathrm{K}$ \\
\hline \hline
\end{tabular}

The measured and predicted temperature profiles for the unaged motorettes are plotted in Fig. 8, where an excellent match is visible (average error $<1 \%$ ).

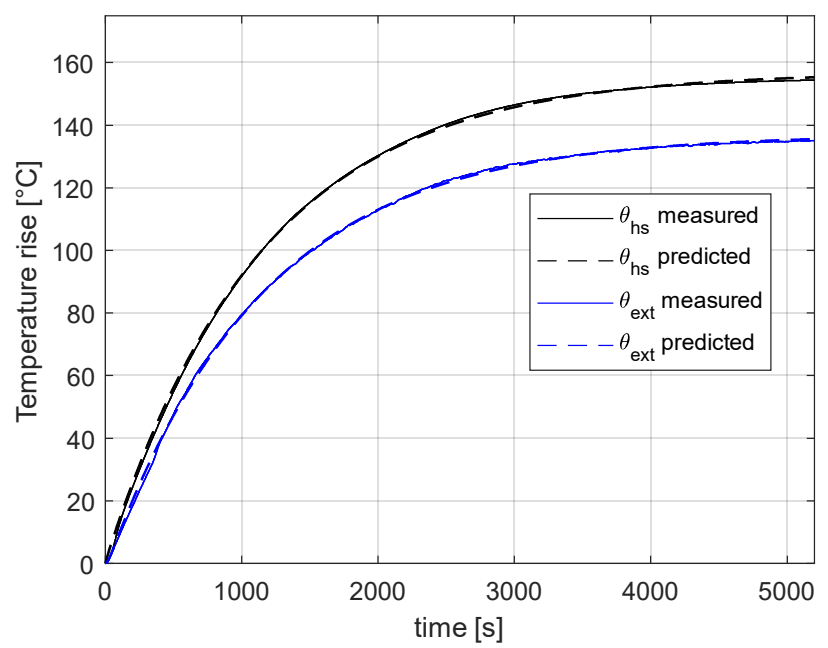

Fig. 8. Measured and LPTN-predicted temperature profiles for the unaged motorettes.

\section{FE thermal model calibration}

The measured steady-state hot-spot and stator core temperatures are used in this sub-section for fine-tuning the FE thermal model presented in Section III.B. Knowing the stator core material, a thermal conductivity of $157 \mathrm{~W} / \mathrm{m} / \mathrm{K}$ is set in the radial direction. Accordingly, the parameter optimization is carried out only on the slot thermal conductivity $k_{w}$ and on the natural air convection coefficient $h_{\text {conv. }}$.

After a sensitivity analysis, the optimized values listed in Table III are found. These fall within the range provided by the existing literature [18-21]. Fig. 9 reports the result of a steady-state thermal simulation, obtained through the FE model, fine-tuned for the unaged motorette fed with 1.5 A. As for the LPTN, even the FE model can predict the motorette temperature rise with an excellent accuracy (the temperature mismatch is below $2{ }^{\circ} \mathrm{C}$ for both $\theta_{h s}$ and $\theta_{a m b}$ - cfr. Fig. 8).

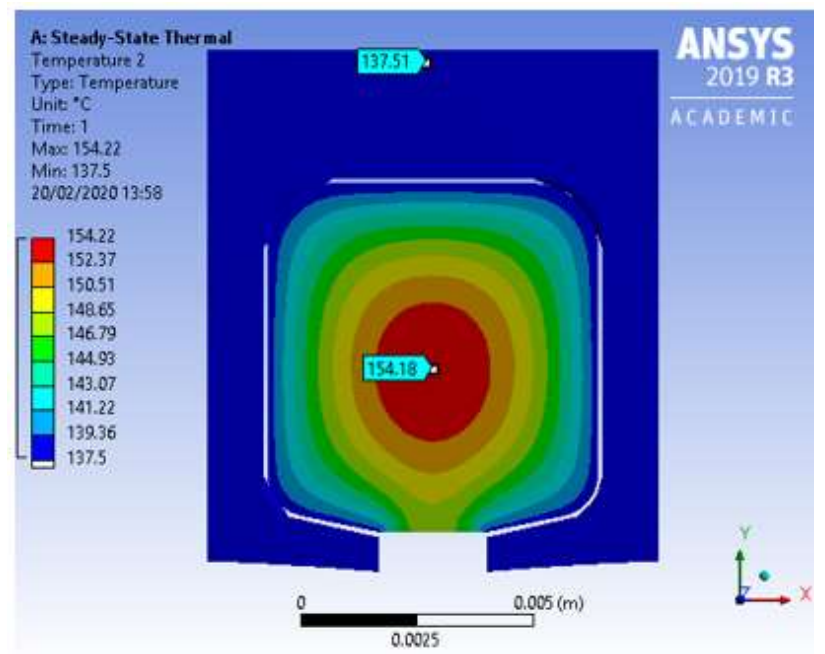

Fig. 9. Steady-state temperature distribution for the unaged motorette.

TABLE III

OPTIMIZED THERMAL PARAMETERS FOR THE UNAGED FE MODEL

\begin{tabular}{cc}
\hline \hline Parameter & Value \\
\hline$k_{w}$ & $0.295 \mathrm{~W} / \mathrm{m} / \mathrm{K}$ \\
$h_{\text {conv }}$ & $45 \mathrm{~W} / \mathrm{m}^{2} / \mathrm{K}$ \\
\hline \hline
\end{tabular}




\section{INFLUENCE OF THERMAL AGING}

An LPTN and a FE thermal model of the case-study PMSM have been built and experimentally calibrated in Sections III and IV respectively. The relationship between thermal aging and their parameters variation is experimentally investigated in this Section.

\section{A. On the thermal aging of insulating materials}

The insulation system of the case-study PMSM features:

1. Turn-to-turn insulation, consisting in a thin $(\approx 30 \mu \mathrm{m})$ layer of organic enamel (polyester-imide, over-coated with polyimide-amide);

2. Epoxy resin impregnation;

3. A single layer $(0.13 \mathrm{~mm})$ of Nomex ${ }^{\circledR}$ paper (aromatic polyamide).

Each one of the listed materials is a polymer, that, when exposed to high temperatures, can experience a so-called chain-end degradation [22]. Namely, the last monomer drops out of the polymeric chain, leading to a process of "depolymerization" [22]. On a macroscopic scale, the thermal degradation process causes a variation of the thermo-physical properties of the EM's insulation sub-systems, and supposedly can have an impact on the thermal models parameters.

For evaluating the extent of such an aging effect, the same two motorettes shown in Fig. 6 are exploited. These are subjected to an accelerated thermal aging campaign, characterized by a set of thermal exposure sub-cycles, shortly followed by the thermal models' re-calibration (procedure detailed in Section IV). The flow-chart of the full test procedure is summarized in Fig. 10. The motorettes are thermally exposed to a constant temperature of $230{ }^{\circ} \mathrm{C}$, i.e. 30 ${ }^{\circ} \mathrm{C}$ above the insulation thermal class. This temperature level is considered adequate for accelerating the thermal aging process, but without excessively stressing the insulation system through secondary aging effects (which would be unrealistic for EMs operating under "standard" conditions).

As the impregnation resin is a thermosetting material, the complete cross-linking of its polymeric chains is achieved upon temperature application [23]. This process is colloquially identified as "curing", and for the motorettes at hand has been carried out after the impregnation procedure, by a thermal exposure of 12 hours at $165^{\circ} \mathrm{C}$, as suggested by the resin manufacturer.

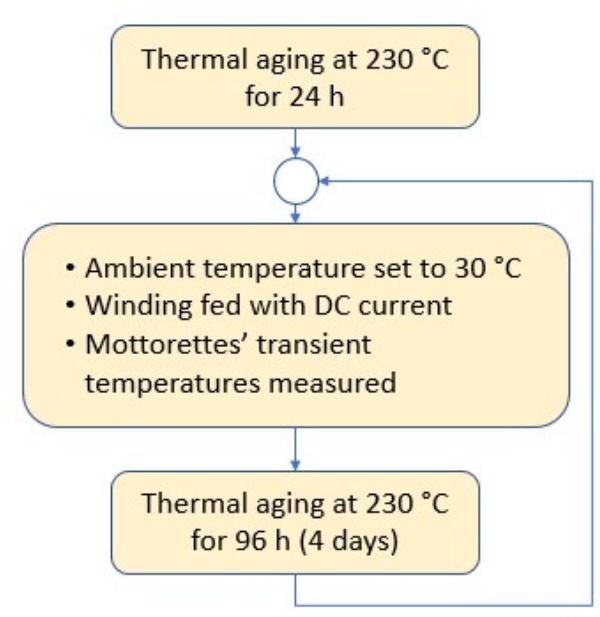

Fig. 10. Flow chart of the experimental procedure.
Nonetheless, the first cycle of thermal aging at $230{ }^{\circ} \mathrm{C}$ is purposely stopped after 24 hours in order to perform an initial calibration of the thermal models. Indeed, it is assumed that the resin's polymeric chain cross-linking will continue even after the standard, suggested curing time. For the remaining aging cycles the thermal exposure time is set to 96 hours (i.e., four days). The procedure (i.e., aging plus thermal models calibration) is repeated until a noticeable $\left(\geq 2{ }^{\circ} \mathrm{C}\right)$ thermal behavior difference (with respect to the previous cycle) is detected.

\section{B. Results presentation}

The measured hot-spot temperature profiles, for four different aging levels are reported in Fig. 11. Clearly, the hot-spot temperature is influenced by the extent of thermal aging. In particular, the more the insulation system ages, the highest becomes $\theta_{h s}$. Conversely, the thermal aging does not seem to have a strong effect on the thermal profile trend / shape. In other words, only the conductivities vary with thermal aging, whilst the capacitances are only slightly affected. This latter aspect is pointed out in Fig. 12, where the temperature variations (i.e., aged minus unaged) are plotted for three thermal exposure times. Essentially, the temperature variation reaches its "steady-state" value shortly after the DC current is applied to the winding. At the end of the last aging cycle (i.e., 216 hours) a hot-spot temperature change of more than $12{ }^{\circ} \mathrm{C}$ is noted. As expected, even after only 24 hours of aging, $\theta_{h s}$ is higher than that measured in the unaged motorette by more than $5^{\circ} \mathrm{C}$. This mismatch confirms that the resin's bonds cross-linking continues even after the epoxy's manufacturer suggested curing time.

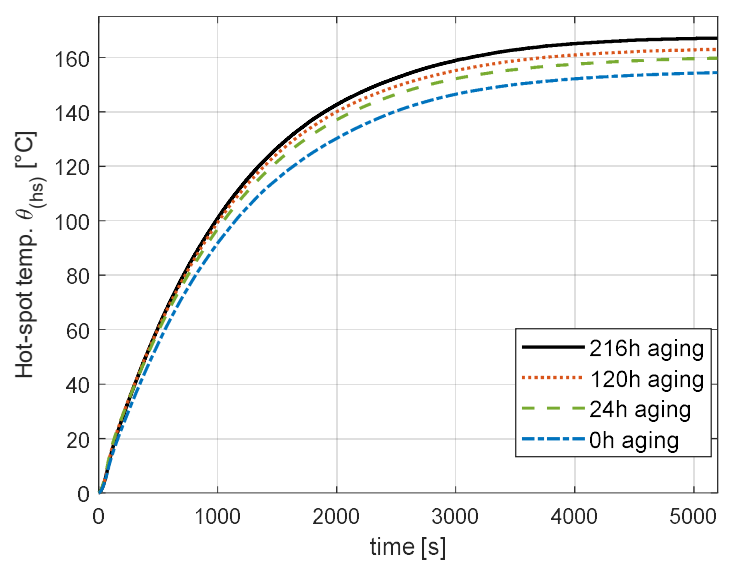

Fig. 11. Hot-spot temperature profiles at four different thermal aging levels.

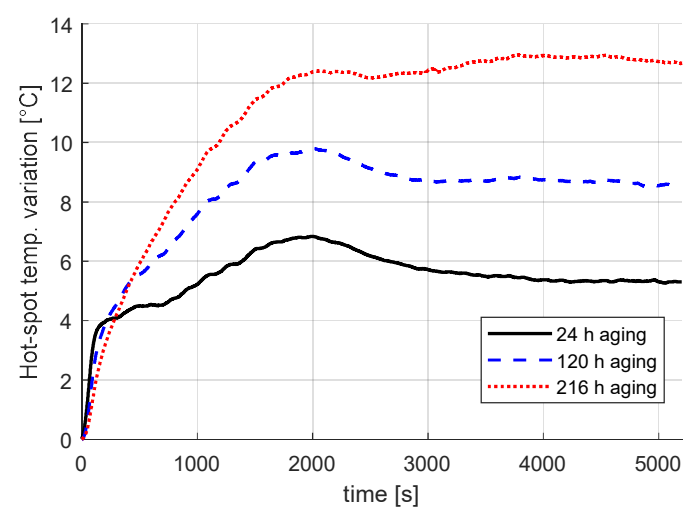

Fig. 12. Hot-spot temperature variation with respect to the unaged motorette. 


\section{LPTN's parameters variation with aging}

The 2-node LPTN can be now re-calibrated for precisely matching the motorette's hot-spot temperature profile, at any level of thermal aging. From the results summarized in Figs. 11 and 12, it is clear that the LPTN's element which is mostly influenced by aging is $R_{e q}$ (cfr. Fig. 3). In fact, it is fair to state that the natural convection resistance (i.e., $R_{\text {conv }}$ ) is not directly affected by the insulation aging. Thus, its previously calibrated value (i.e., $64.2 \mathrm{~K} / \mathrm{W}$ ) is still valid even for the thermally-aged motorette. Looking at the temperature profile variations reported in Fig. 12, it is also possible to assume that the thermal capacities are unaffected by aging.

The fine-tuning procedure detailed in Section IV.B is repeated for obtaining the "aged" $R_{e q}$ values. These are listed in Table IV where they are linked to the respective thermal aging exposure time. The more the insulation system ages the higher becomes $R_{e q}$. In other words, the thermal aging of the insulation systems causes an increment of the equivalent thermal resistance between the winding hot-spot and the motorette outer surface node. This means that the more an EM ages, the poorer becomes its heat dissipation capability.

It is fair to hypothesize that such an effect is mainly due to the equivalent slot thermal conductivity varying throughout the EM's lifetime. This aspect is investigated in the next subsection through the aid of the FE model.

TABLE IV

OPtimized Equivalent THeRmal Resistance For the ‘AgED’ LPTN

\begin{tabular}{cc}
\hline $\begin{array}{c}\text { Thermal exposure } \\
\text { time at } 230\end{array}{ }^{\circ} \mathbf{C}$ & $\begin{array}{c}\boldsymbol{R}_{\text {eq }} \\
{[\mathbf{K} / \mathbf{W}]}\end{array}$ \\
\hline $24 h$ & 12.5 \\
$120 h$ & 14.1 \\
$216 \mathrm{~h}$ & 16.1 \\
\hline \hline
\end{tabular}

\section{Slot's thermal conductivity variation with aging}

The FE model introduced in Section III.B and validated in Section IV.C is exploited for quantifying the change of the slot thermal conductivity in a thermally aged EM. For fulfilling the task, it is assumed that the convection coefficient between the stator outer surface and the ambient air is not affected by thermal aging (as in the previous examination). Accordingly, a sensitivity analysis is performed on the thermal FE model, by acting exclusively on $k_{w}$ (cfr. Table III). More precisely, for each thermal aging level/time there is an optimized $k_{w}$ value, so that the FE model can precisely match the steady-state, hot-spot temperatures of Fig. 11. These are listed in Table $\mathrm{V}$, where the decrement of the slot conductivity with thermal aging is observable.

For completeness, and for the sake of representation clarity, Fig. 13 shows the slot temperature distribution obtained through a FE simulation, for two different thermal aging levels, namely, 0 hours (i.e., unaged) and 216 hours.

TABLE V

Slot Measured Temperature And Thermal Conductivity vs. Thermal Aging

\begin{tabular}{ccc}
\hline $\begin{array}{c}\text { Thermal exposure } \\
\text { time at } 230\end{array}{ }^{\circ} \mathbf{C}$ & $\begin{array}{c}\text { Steady-state hot-spot } \\
\text { Temperature }\left[{ }^{\circ} \mathbf{C}\right]\end{array}$ & $\begin{array}{c}\text { Slot Conductivity } \boldsymbol{k}_{\boldsymbol{w}} \\
{[\mathbf{W} / \mathbf{m} / \mathbf{K}]}\end{array}$ \\
\hline 0 h (unaged) & 154 & 0.295 \\
$24 h$ & 159 & 0.194 \\
$120 h$ & 163 & 0.164 \\
$216 \mathrm{~h}$ & 168 & 0.154 \\
\hline \hline
\end{tabular}

It is possible to note that the-hot spot temperatures (i.e. unaged vs. aged) matches those recorded experimentally (see Fig. 11), confirming the excellent accuracy of the FE model. As a consequence, the thermal conductivity data in Table $\mathrm{V}$ can be considered fairly precise.

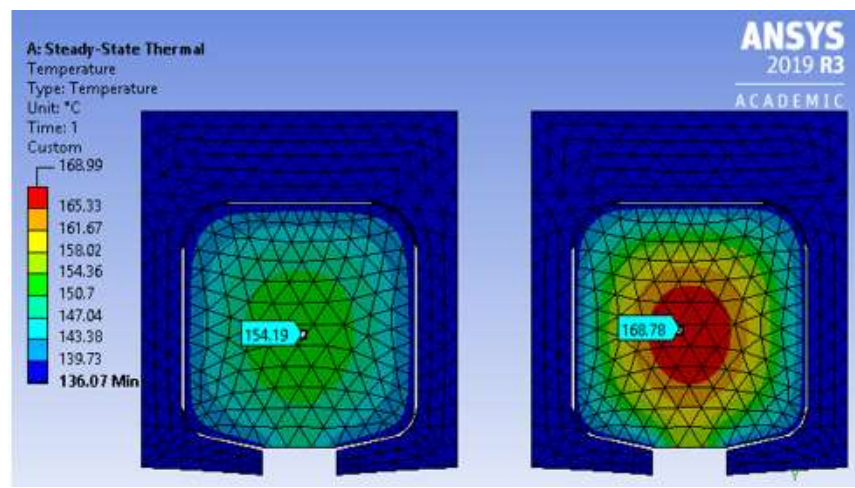

Fig. 13. Temperature distribution from thermal FE for the unaged (left) and thermally aged $(216 \mathrm{~h})$ (right) motorette.

\section{DISCUSSION}

From the results and analyses reported in Section V, it is clear that thermal aging can strongly affect how heat is transferred within an EM. The temperature hot-spot in the motorette thermally aged for 216 hours is $9 \%$ higher with respect to the unaged case. Such a temperature increment is mainly due to the winding equivalent thermal conductivity decreasing by $48 \%$ from the unaged to the thermally aged (216 hours) case.

Based on this outcome, an important consideration / guideline to EM designers can be provided. Namely, the thermal behavior evaluation (i.e., thermal models calibration) of an EM should be carried out on a thermally aged EM / motorette, in order to deliver reliable temperature predictions and rely on more conservative estimations. For the EM at hand, a thermal aging temperature of $230{ }^{\circ} \mathrm{C}$ is considered adequate for carrying out the aforementioned analysis. However, the latter should be selected depending on the insulation system of the modelled EM. The same consideration is valid for the thermal exposure time. Here, the thermal aging is stopped after $216 \mathrm{~h}$, as further thermal exposures did not cause any substantial hot-spot temperature variation. More precisely, the exposure time should be linked to the percent 'consumed insulation lifetime' according to the acceptable reliability level. Hence, an essential prerequisite is the obtainment of the thermal endurance curve (i.e., the Arrhenius plot) [24] of the insulation system under study.

\section{CONCLUSIONS}

Thermal modeling is a critical aspect in the design of electrical machines. Both lumped parameters thermal networks and finite element models are excellent tools for predicting the temperature distribution. Their fine-tuning and calibration, necessary for ensuring temperature prediction accuracy, are often performed on unaged prototypes / motorettes, causing misleading results, as the machine ages.

This paper demonstrates that thermal aging can have a substantial impact on the heat transfer capability within an electrical machine. In particular, the winding equivalent thermal conductivity can decrease by circa $50 \%$ as a result of the insulation thermal aging. This leads to a considerable 
hot-spot temperature increment, whose magnitude rises as thermal aging accumulates. The proposed methodologies and presented analyses can be readapted to different electrical machines typologies and cooling arrangements, for achieving an accurate thermal modeling throughout the electrical machine lifetime.

\section{REFERENCES}

[1] H. S. McNaughton, "6 - Insulation," in Electric Motor Handbook, B. J. Chalmers, Ed.: Butterworth-Heinemann, 1988, pp. 332-392.

[2] R. H. Jansen, C. Bowman, A. Jankovsky, R. Dyson, and J. Felder, "Overview of NASA Electrified Aircraft Propulsion Research for Large Subsonic Transports," AIAA Propulsion and Energy 2017 Forum; 10 12 Jul. 2017; Atlanta, GA; United States. Available: https://ntrs.nasa.gov/search.jsp? $R=20170006235$ Accessed: Dec. 2017.

[3] M. Lukic, P. Giangrande, A. Hebala, S. Nuzzo, and M. Galea, "Review, Challenges, and Future Developments of Electric Taxiing Systems," IEEE Transactions on Transportation Electrification, vol. 5, no. 4, pp. 1441-1457, 2019.

[4] V. Madonna, G. Migliazza, P. Giangrande, E. Lorenzani, G. Buticchi, and M. Galea, "The Rebirth of the Current Source Inverter: Advantages for Aerospace Motor Design," IEEE Industrial Electronics Magazine, vol. 13, no. 4, pp. 65-76, 2019.

[5] V. Madonna, P. Giangrande, and M. Galea, "Electrical Power Generation in Aircraft: Review, Challenges, and Opportunities," IEEE Transactions on Transportation Electrification, vol. 4, no. 3, pp. 646659, 2018.

[6] I. Petrov, P. M. Lindh, M. Niemela, E. Scherman, O. Wallmark, and J. J. Pyrhonen, "Investigation of a Direct Liquid Cooling System in a Permanent Magnet Synchronous Machine," IEEE Transactions on Energy Conversion, pp. 1-1, 2019.

[7] F. Marcolini, G. D. Donato, and F. Caricchi, "Direct Oil Cooling of EndWindings in Torus-Type Axial-Flux Permanent-Magnet Machines," in 2019 IEEE Energy Conversion Congress and Exposition (ECCE), 2019, pp. $5645-5651$.

[8] M. Garibaldi, C. Gerada, I. Ashcroft, R. Hague, and H. Morvan, "The impact of additive manufacturing on the development of electrical machines for MEA Applications: A feasibility study," in MEA2015 More Electric Aircraft, 2015.

[9] R. Wrobel and B. Mecrow, "Additive Manufacturing in Construction of Electrical Machines - A Review," in 2019 IEEE Workshop on Electrical Machines Design, Control and Diagnosis (WEMDCD), 2019, vol. 1, pp. $15-22$.

[10] V. Madonna, P. Giangrande, and M. Galea, "Introducing Physics of Failure Considerations in the Electrical Machines Design," in 2019 IEEE International Electric Machines \& Drives Conference (IEMDC), 2019, pp. 2233-2238.

[11] H. Yeo, H. Park, J. Seo, S. Jung, J. Ro, and H. Jung, "Electromagnetic and Thermal Analysis of a Surface-Mounted Permanent-Magnet Motor with Overhang Structure," IEEE Transactions on Magnetics, vol. 53, no. 6 , pp. 1-4, 2017

[12] C. Sciascera, P. Giangrande, C. Brunson, M. Galea, and C. Gerada, "Optimal design of an electro-mechanical actuator for aerospace application," in IECON 2015 - 41st Annual Conference of the IEEE Industrial Electronics Society, 2015, pp. 001903-001908.

[13] A. Boglietti, E. Carpaneto, M. Cossale, and S. Vaschetto, "StatorWinding Thermal Models for Short-Time Thermal Transients: Definition and Validation," IEEE Transactions on Industrial Electronics, vol. 63, no. 5, pp. 2713-2721, 2016.
[14] P. Giangrande et al., "Considerations on the Development of an Electric Drive for a Secondary Flight Control Electromechanical Actuator," IEEE Transactions on Industry Applications, vol. 55, no. 4, pp. 3544$3554,2019$.

[15] A. Boglietti, M. Cossale, M. Popescu, and D. A. Staton, "Electrical Machines Thermal Model: Advanced Calibration Techniques," IEEE Transactions on Industry Applications, vol. 55, no. 3, pp. 2620-2628, 2019.

[16] A. Boglietti, M. Cossale, S. Vaschetto, and T. Dutra, "Winding Thermal Model for Short-Time Transient: Experimental Validation in Operative Conditions," IEEE Transactions on Industry Applications, vol. 54, no. 2, pp. 1312-1319, 2018.

[17] S. Ayat, H. Liu, F. Chauvicourt, and R. Wrobel, "Experimental Derivation of Thermal Parameters of the Stator- Winding Region in Thermal Analysis of PM Electrical Machines," in IECON 2018 - 44th Annual Conference of the IEEE Industrial Electronics Society, 2018, pp. 496-501.

[18] A. Boglietti, A. Cavagnino, and D. Staton, "Determination of Critical Parameters in Electrical Machine Thermal Models," IEEE Transactions on Industry Applications, vol. 44, no. 4, pp. 1150-1159, 2008

[19] A. Boglietti, M. Cossale, S. Vaschetto, and T. Dutra, "Thermal Conductivity Evaluation of Fractional-Slot Concentrated-Winding Machines," IEEE Transactions on Industry Applications, vol. 53, no. 3, pp. 2059-2065, 2017.

[20] R. Wrobel, S. J. Williamson, J. D. Booker, and P. H. Mellor, "Characterizing the in situ Thermal Behavior of Selected Electrical Machine Insulation and Impregnation Materials," IEEE Transactions on Industry Applications, vol. 52, no. 6, pp. 4678-4687, 2016.

[21] P. Romanazzi, J. Gyselinck, M. Bruna, and D. A. Howey, "Electromagnetic and thermal homogenisation of an electrical machine slot," in 2016 XXII International Conference on Electrical Machines (ICEM), 2016, pp. 1643-1649.

[22] G. G. Raju, Dielectrics in electric fields. CRC press, 2016.

[23] D. I. Bower, "An introduction to polymer physics," ed: American Association of Physics Teachers, 2003.

[24] V. Madonna, P. Giangrande, G. Migliazza, G. Buticchi, and M. Galea, "A Time-Saving Approach for the Thermal Lifetime Evaluation of Low Voltage Electrical Machines," IEEE Transactions on Industrial Electronics, pp. 1-1, 2019.

\section{BIOGRAPHIES}

Vincenzo Madonna received the MSc degree in Electrical Engineering from the University of Bologna, Italy, in 2016 and the PhD degree in Electrical Machines Design from the University of Nottingham, UK in 2020. In 2016 he was awarded a prestigious Marie Curie Doctoral Fellowship and joined the Institute for Aerospace Technology in Nottingham. He is currently a Research Fellow with the Propulsion Futures Beacon of Excellence at the university of Nottingham. His research interests include design, thermal management and lifetime prediction modelling of electrical machines.

Paolo Giangrande received his $\mathrm{PhD}$ in electrical engineering at the Politecnico of Bari in 2011. Since January 2012, he is Research Fellow at the University of Nottingham (UK), within the Power Electronics, Machines and Control (PEMC) group. His main research interests include design and testing of electromechanical actuators for aerospace, thermal management of high-performance electric drives and reliability of electrical machines.

Michael Galea received his $\mathrm{PhD}$ in electrical machines design from the University of Nottingham, where he has also worked as a Research Fellow. $\mathrm{He}$ is currently the Head of the School of Aerospace in the University of Nottingham, Ningbo, China. His main research interests are design, analysis and thermal management of electrical machines and drives, the more electric aircraft and electrified and hybrid propulsion 